\title{
SEOM clinical guideline for the management of cutaneous melanoma (2020)
}

\author{
M. Majem ${ }^{1}$ (1) J. L. Manzano ${ }^{2} \cdot$ I. Marquez-Rodas $^{3} \cdot \mathrm{K}$ Mujika $^{4} \cdot$ E. Muñoz-Couselo $^{5} \cdot$ E. Pérez-Ruiz $^{6}$. \\ L. de la Cruz-Merino ${ }^{7,8} \cdot$ E. Espinosa $^{9} \cdot$ M. Gonzalez-Cao ${ }^{10} \cdot$ A. Berrocal ${ }^{11}$
}

Accepted: 2 December 2020 / Published online: 2 March 2021

(c) The Author(s) 2021

\begin{abstract}
Melanoma affects about 6000 patients a year in Spain. A group of medical oncologists from Spanish Society of Medical Oncology (SEOM) and Spanish Multidisciplinary Melanoma Group (GEM) has designed these guidelines to homogenize the management of these patients. The diagnosis must be histological and determination of BRAF status has to be performed in patients with stage $\geq$ III. Stage I-III resectable melanomas will be treated surgically. In patients with stage III melanoma, adjuvant treatment with immunotherapy or targeted therapy is also recommended. Patients with unresectable or metastatic melanoma will receive treatment with immunotherapy or targeted therapy, the optimal sequence of these treatments remains unclear. Brain metastases require a separate consideration, since, in addition to systemic treatment, they may require local treatment. Patients must be followed up closely to receive or change treatment as soon as their previous clinical condition changes, since multiple therapeutic options are available.
\end{abstract}

Keywords Melanoma $\cdot$ Adjuvant treatment metastatic treatment $\cdot$ Staging

All authors have contributed equally to the present manuscript.

All authors are members of the Spanish Society of Medical Oncology (SEOM) and Spanish Multidisciplinary Melanoma Group (GEM).

M. Majem
mmajem@santpau.cat
J. L. Manzano
jmanzano@iconcologia.net
I. Marquez-Rodas
ivanpantic@ hotmail.com
K. Mujika
kmujika@onkologikoa.org
E. Muñoz-Couselo
emunoz@vhio.net
E. Pérez-Ruiz
eliperu@gmail.com
L. de la Cruz-Merino
lucme12@yahoo.es
E. Espinosa
eespinosa00@hotmail.com
M. Gonzalez-Cao
mgonzalezcao@oncorosell.com

M. Majem

mmajem@santpau.cat

J. L. Manzano

jmanzano@iconcologia.net

I. Marquez-Rodas

ivanpantic@hotmail.com

K. Mujika

E. Muñoz-Couselo

emunoz@vhio.net

E. Pérez-Ruiz
eliperu@gmail.com
L.de la Cruz-Merino
lucme12@yahoo.es
E. Espinosa
eespinosa00@hotmail.com
M. Gonzalez-Cao
mgonzalezcao@oncorosell.com
A. Berrocal

berrocal.alf@gmail.com

1 Department of Medical Oncology, Hospital de la Santa Creu i Sant Pau, c/Sant Antoni Maria Claret 167, 08025 Barcelona, Spain

2 Department of Medical Oncology, H. Germans Trias i Pujol, Catalan Institute of Oncology, ICO-Badalona, Badalona, Spain

3 Department of Medical Oncology, Instituto de Investigación Sanitaria Gregorio Marañón and CIBERONC, Madrid, Spain

4 Department of Medical Oncology, UGC de Oncología de Gipuzkoa, OSI Donostialdea-Onkologikoa, Guipúzcoa, Spain

5 Department of Medical Oncology, Vall d'Hebron Institute of Oncology (VHIO), Hospital Vall d'Hebron Barcelona, Barcelona, Spain

6 Department of Medical Oncology, Hospital Costa del Sol and UGC Oncol, Instituto de Investigación Biomédica de Málaga (IBIMA), Hospital Universitario Regional Virgen Victoria, Málaga, Spain 


\section{Methodology}

The authors have reviewed the published clinical guidelines, as well as clinical trials from which the aspects referred to in these guidelines can be concluded. Each author has been responsible for reviewing a part of the guideline that has been shared and discussed among all the authors to reach a consensus. Finally, the degrees of evidence and recommendation have been established based on the recommendations for the development of guidelines $[1,2]$.

\section{Incidence and epidemiology}

The annual incidence of melanoma in Europe is $<10-25 / 100.000$, in the US is 20-30/100.000 and in Australia 50-60/100.000 [3]. It is expected an increase in the next years, and therefore, there is a need to improve prevention and early diagnosis measures [4]. In Spain, an increase in the melanoma mortality rate was observed in the last decades of the twentieth century; however, later, stabilization was observed in women and a decrease in middle age and young men [5, 6]. In 2020, the estimated new cases of melanoma in Spain are 6179 [7].

Ultraviolet radiation is the most important risk factor, especially if intermittent sun exposure, particularly early in life [8]. Individuals with skin types I and II have the highest risk of developing melanoma, as well as individuals with a high numbers of typical nevi, large congenital nevi, and atypical nevi $[9,10]$. About $10 \%$ of melanomas occur in patients with familial history of melanoma and can present a germline mutation; CDKN2A is the main gene involved [11]. Physical protection is the best prevention of melanoma, and regular use of sunscreen reduces the incidence of cutaneous melanoma (level of evidence 1, grade of recommendation A) [12].

\footnotetext{
7 Department of Medical Oncology, Hospital Universitario Virgen Macarena, Seville, Spain

8 Medicine Department, Universidad de Sevilla, Seville, Spain

9 Department of Medical Oncology, Hospital Universitario La Paz, CIBERONC, Madrid, Spain

10 Oncology Department (IOR), Hospital Dexeus, Barcelona, Spain

11 Department of Medical Oncology, Consorcio Hospital General Universitario de Valencia, Valencia, Spain
}

\section{Diagnosis and pathology}

Clinical analysis of suspicious lesions includes three aspects: (1) ABCD rule (Asymmetry, Border irregularities, Color heterogeneity, and Dynamics or evolution in the color, size, or elevation), (2) the ugly duckling sign (the lesion is different from the rest in the same patient), and (3) chronological analysis of changes: assessment of rapid growth in a previous lesion [13]. Dermatoscopy by an experienced physician is recommended for the diagnosis of pigmented lesions (Level of evidence $1 \mathrm{~b}$, grade of recommendation A) [14]. Whole-body photography and digital dermatoscopy are useful in people at high risk of melanoma, especially in early diagnosis (Level of evidence $2 b$, grade of recommendation B) [15]. Reflectance confocal microscopy can be helpful in lesions difficult to diagnose by visual inspection and dermatoscopy (Level of evidence 2b, grade of recommendation B) [16]. All suspicious lesions must be confirmed histologically by excisional biopsy following the eighth edition of the American Joint Committee on Cancer (AJCC 8th edition) [17].

\section{Molecular testing}

Determination of BRAF V600 status is mandatory in patients with resectable or unresectable stage III or IV melanoma (Level of evidence 1, grade of recommendation A). Determination of C-KIT and NRAS status is recommended in BRAF wild-type patients (Level of evidence 2, grade of recommendation C) [18, 19]. A new melanoma subtype with NF1 mutation has recently been defined, but its clinical implications are unknown [20]. Programmed death ligand 1 (PD-L1) expression can be tested in resectable or unresectable stage III and IV, although its determination is not mandatory, since negative cases can respond to anti-PD-1 treatments.

\section{Staging (Table 1)}

TNM staging in melanoma includes physical examination of the entire body. In pT1b-pT4b melanoma, ultrasound (US) for locoregional lymph-node metastasis, and/or computed tomography (CT) or positron emission tomography (PET) scans and brain magnetic resonance imaging (MRI), is recommended for proper tumor assessment (Level of evidence 3, grade of recommendation A) [17]. 
Table 1 Melanoma staging AJCC 8th edition

\begin{tabular}{lll}
\hline T category & Thickness & Ulceration status \\
\hline TX: Primary tumor thickness cannot be assessed (e.g., diagnosis by curettage) & Not applicable & Not applicable \\
T0: No evidence of primary tumor (e.g., unknown primary or completely regressed & Not applicable & Not applicable \\
melanoma) & Not applicable & Not applicable \\
Tis (melanoma in situ) & $\leq 1.0 \mathrm{~mm}$ & Unknown or unspecified \\
T1 & $<0.8 \mathrm{~mm}$ & Without ulceration \\
T1a & $<0.8 \mathrm{~mm}$ & With ulceration \\
T1b & $0.8-1.0 \mathrm{~mm}$ & With or without ulceration \\
& $>1.0-2.0 \mathrm{~mm}$ & Unknown or unspecified \\
T2 & $>1.0-2.0 \mathrm{~mm}$ & Without ulceration \\
T2a & $>1.0-2.0 \mathrm{~mm}$ & With ulceration \\
T2b & $>2.0-4.0 \mathrm{~mm}$ & Unknown or unspecified \\
T3 & $>2.0-4.0 \mathrm{~mm}$ & Without ulceration \\
T3a & $>2.0-4.0 \mathrm{~mm}$ & With ulceration \\
T3b & $>4.0 \mathrm{~mm}$ & Unknown or unspecified \\
T4 & $>4.0 \mathrm{~mm}$ & Without ulceration \\
T4a & $>4.0 \mathrm{~mm}$ & With ulceration \\
T4b & & Pres
\end{tabular}

$\mathrm{N}$ category No. of tumor-involved regional lymph nodes

Presence of in-transit, satellite, and/or microsatellite metastases

\begin{tabular}{|c|c|c|}
\hline NX & $\begin{array}{l}\text { Regional nodes not assessed (e.g., sentinel lymph-node biopsy not performed, regional nodes } \\
\text { previously removed for another reason) } \\
\text { Exception: pathological } \mathrm{N} \text { category is not required for } \mathrm{T} 1 \text { melanomas, use clinical } \mathrm{N} \text { information }\end{array}$ & No \\
\hline No & No regional metastases detected & No \\
\hline N1 & $\begin{array}{l}\text { One tumor-involved node or any number of in-transit, satellite, and/or microsatellite metastases } \\
\text { with no tumor-involved nodes }\end{array}$ & \\
\hline N1a & One clinically occult (i.e., detected by SLN biopsy) & No \\
\hline $\mathrm{N} 1 \mathrm{~b}$ & One clinically detected & No \\
\hline $\mathrm{N} 1 \mathrm{c}$ & No regional lymph-node disease & Yes \\
\hline $\mathrm{N} 2$ & $\begin{array}{l}\text { Two or three tumor-involved nodes or any number of in-transit, satellite, and/or microsatellite } \\
\text { metastases with one tumor-involved node }\end{array}$ & \\
\hline $\mathrm{N} 2 \mathrm{a}$ & Two or three clinically occult (i.e., detected by SLN biopsy) & No \\
\hline $\mathrm{N} 2 \mathrm{~b}$ & Two or three, at least one of which was clinically detected & No \\
\hline $\mathrm{N} 2 \mathrm{c}$ & One clinically occult or clinically detected & Yes \\
\hline N3 & $\begin{array}{l}\text { Four or more tumor-involved nodes or any number of in-transit, satellite, and/or microsatellite } \\
\text { metastases with two or more tumor-involved nodes, or any number of matted nodes without or } \\
\text { with in-transit, satellite, and/or microsatellite metastases }\end{array}$ & \\
\hline $\mathrm{N} 3 \mathrm{a}$ & Four or more clinically occult (i.e., detected by SLN biopsy) & No \\
\hline $\mathrm{N} 3 \mathrm{~b}$ & $\begin{array}{l}\text { Four or more, at least one of which was clinically detected, or the presence of any number of mat- } \\
\text { ted nodes }\end{array}$ & No \\
\hline $\mathrm{N} 3 \mathrm{c}$ & $\begin{array}{l}\text { Two or more clinically occult or clinically detected and/or presence of any number of matted } \\
\text { nodes }\end{array}$ & Yes \\
\hline M category & Anatomic site & LDH level \\
\hline M0 & No evidence of distant metastasis & Not applicable \\
\hline M1 & Evidence of distant metastasis & See below \\
\hline $\begin{array}{l}\text { M1a } \\
\qquad \text { M1a(0) } \\
\text { M1a (1) }\end{array}$ & Distant metastasis to skin, soft tissue including muscle, and/or nonregional lymph node & $\begin{array}{l}\text { Not recorded or unspecified } \\
\text { Not elevated } \\
\text { Elevated }\end{array}$ \\
\hline $\begin{array}{l}\text { M1b } \\
\text { M1b(0) } \\
\text { M1b (1) }\end{array}$ & Distant metastasis to lung with or without M1a sites of disease & $\begin{array}{l}\text { Not recorded or unspecified } \\
\text { Not elevated } \\
\text { Elevated }\end{array}$ \\
\hline
\end{tabular}


Table 1 (continued)

\begin{tabular}{|c|c|c|c|}
\hline M category & \multicolumn{2}{|l|}{ Anatomic site } & LDH level \\
\hline M1c & \multirow{3}{*}{\multicolumn{2}{|c|}{ Distant metastasis to non-CNS visceral sites with or without M1a or M1b sites of disease }} & Not recorded or unspecified \\
\hline $\operatorname{M1c}(0)$ & & & Not elevated \\
\hline M1c (1) & & & Elevated \\
\hline M1d & \multirow{3}{*}{\multicolumn{2}{|c|}{ Distant metastasis to CNS with or without M1a, M1b, or M1c sites of disease }} & Not recorded or unspecified \\
\hline $\operatorname{M1d}(0)$ & & & Not elevated \\
\hline M1d (1) & & & Elevated \\
\hline $\mathrm{T}$ & $\mathrm{N}$ & M & Stage group \\
\hline Tis & No & M0 & 0 \\
\hline T1a & No & M0 & IA \\
\hline $\mathrm{T} 1 \mathrm{~b}-\mathrm{T} 2 \mathrm{a}$ & N0 & M0 & IB \\
\hline $\mathrm{T} 2 \mathrm{~b}-\mathrm{T} 3 \mathrm{a}$ & NO & M0 & IIA \\
\hline $\mathrm{T} 3 \mathrm{~b}-\mathrm{T} 4 \mathrm{a}$ & No & M0 & IIB \\
\hline $\mathrm{T} 4 \mathrm{~b}$ & N0 & M0 & IIC \\
\hline Any $\mathrm{T}$, Tis & $\geq \mathrm{N} 1$ & M0 & III \\
\hline Any $\mathrm{T}$ & Any $\mathrm{N}$ & M1 & IV \\
\hline
\end{tabular}

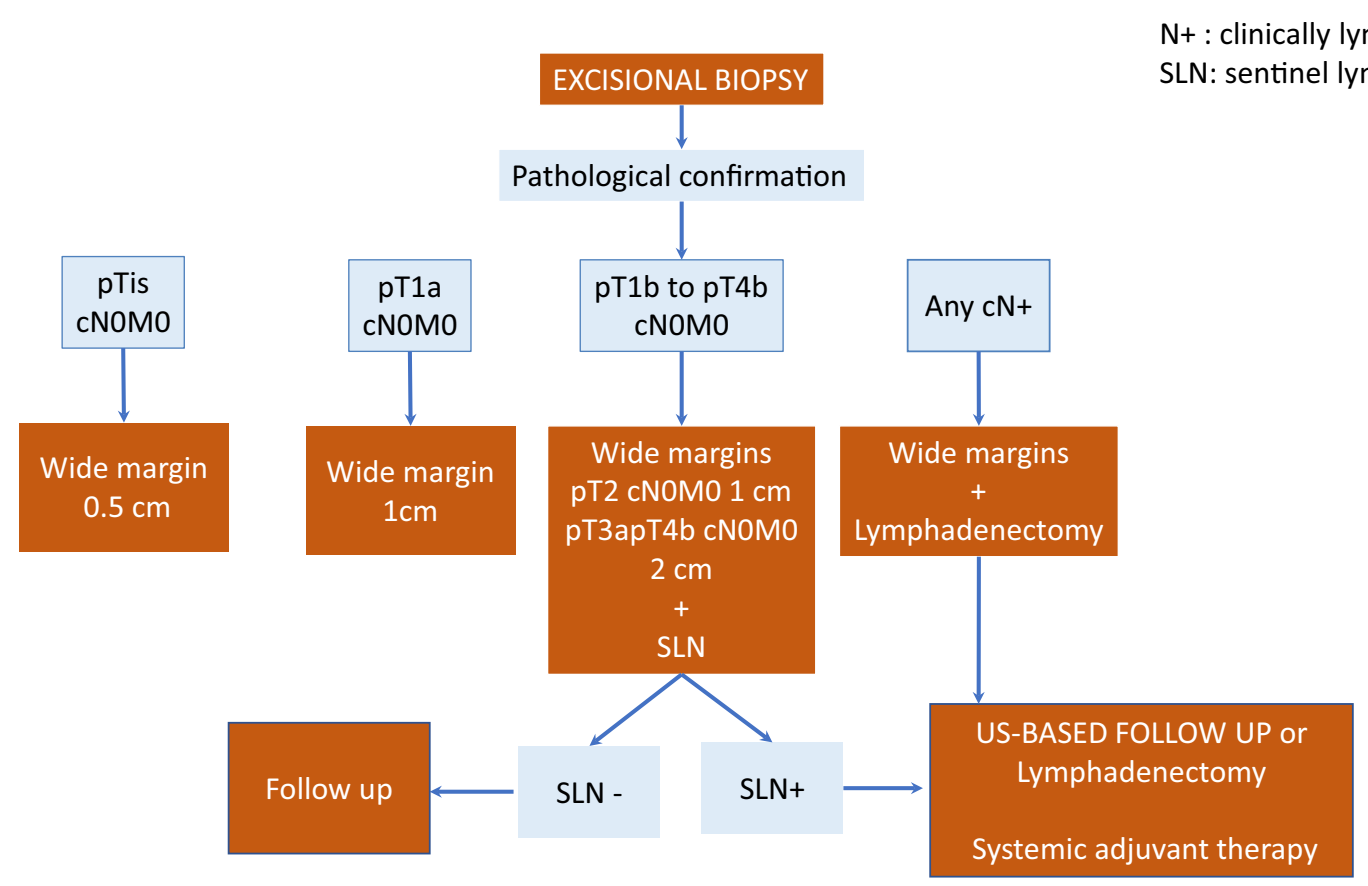

Fig. 1 Treatment algorithm for primary tumors and regional lymph notes

\section{Treatment of localized disease}

\section{Treatment of primary tumors}

Excisional biopsy with a $2 \mathrm{~mm}$ lateral margin and deep subcutaneous margin is indicated for any suspicious lesion (Level of evidence 1a, grade of recommendation A). Upon pathological confirmation of the diagnosis, definitive surgery with wide margins is performed. The deep margin should extend to the fascia, whereas lateral margins will depend on Breslow thickness: $0.5 \mathrm{~cm}$ for in situ melanomas, $1 \mathrm{~cm}$ for tumors with thickness of up to $2 \mathrm{~mm}$, and $2 \mathrm{~cm}$ for $>2 \mathrm{~mm}$ (Level of evidence $1 \mathrm{~b}$, grade of recommendation A) [21]. Figure 1 shows the treatment algorithm for primary tumors.

Sentinel lymph-node biopsy is recommended for melanomas with Breslow $>0.8 \mathrm{~mm}$ of thickness or $<0.8 \mathrm{~mm}$ with ulceration, i.e., melanomas with stage $\geq$ IB of the 
AJCC 8th edition classification (Level of evidence 2a, grade of recommendation A) [22-24].

Complete lymph-node dissection in patients with positive sentinel lymph nodes carries severe morbidity and has shown no impact on survival compared with US-based follow-up (Level of evidence 1b, grade of recommendation A) $[25,26]$. For this reason, complete dissection has been abandoned as routine practice. However, the procedure is recommended in the case of clinically detected regional lymph-node metastases (Level of evidence 4, grade of recommendation C) [27].

Resection of satellite or in-transit metastases is associated with a high risk of local and regional progression. With the advent of effective systemic therapies, this strategy could only be considered in highly selected cases (Level of evidence 4, grade of recommendation C).

\section{Adjuvant therapy}

\section{Adjuvant radiotherapy}

Adjuvant radiotherapy in the local tumor can be considered in cases of inadequate resection margins of lentigo maligna when further resection is not advisable (Level of evidence $3 \mathrm{~b}$, grade of recommendation $\mathrm{B}$. The role of radiotherapy for in-transit metastasis has not been established (Level of evidence 5, grade of recommendation D). Nodal adjuvant radiotherapy reduces the risk of regional recurrence after resection of palpable regional lymph nodes or extracapsular extension [28]. However, it increases the risk of regional toxicity - particularly lymphedema-with no impact on overall survival, so it is not longer routinely recommended (Level of evidence $2 b$, grade of recommendation B) [29]. Radiotherapy may be discussed in resected head and neck melanoma with palpable lymph nodes, where local control is critical and has a lower risk of lymphedema.

\section{Adjuvant systemic therapy}

For patients with complete resection of a cutaneous melanoma, to recommend adjuvant systemic therapy depends upon the risk of disease recurrence, based on the stage at diagnosis, along with a consideration of patient age, comorbidity, and personal preferences. For patients with stage III melanoma, adjuvant immunotherapy with nivolumab or pembrolizumab is indicated; and dabrafenib and trametinib are an alternative for patients with BRAF V600 mutation. In patients with completely resected stage IV, adjuvant nivolumab is also indicated.

Nivolumab for 1 year prolonged RFS at 4-year followup compared with ipilimumab (52\% vs. $41 \%$, HR: 0.71 , $p<0.0001$, respectively) in patients with completely resected stage IIIB, IIIC, or IV. Efficacy was observed both in BRAF mutant and wild-type patients. In the first report of overall survival, with fewer events than expected, OS rates were similar in both treatment groups (78\% Nivolumab and $77 \%$ ipilimumab), taking into account that more patients treated with ipilimumab received subsequent therapy, including immunotherapy (57\% with ipilimumab and $49 \%$ with nivolumab) [30, 31].

Pembrolizumab for 1 year has also shown prolonged RFS compared with placebo in patients with completely resected stage III melanoma at 3.5-year follow-up (59'8\% vs. $41^{\prime} 4 \%$, HR 0,59, $p<0.0001$, respectively). Efficacy was observed both in BRAF mutant and wild-type patients. Pembrolizumab also decreased the 3.5-year incidence of distant metastases as first recurrence and locoregional recurrence only. The S1404 phase III trial compares pembrolizumab with high-dose interferon or high-dose ipilimumab in patients with completely resected high-risk stage III-IVA disease; accrual is complete, and results are pending [32, 33].

Dabrafenib plus trametinib for 1 year showed a longer RFS compared with placebo in completely resected stage III $B R A F$ V600 mutant melanoma at 5 year follow-up (52\% vs. $36 \%$, HR $0.51,95 \%$ CI $0.42-0.61$ ), irrespective of baseline factors. Overall survival, at a median follow-up of 2.8 years, was prolonged with the targeted therapy, but remains immature [34-37].

In summary, in patients with completely resected stage III or IV melanoma, adjuvant immunotherapy and targeted therapies have shown to improve RFS (Level of evidence 1, grade of recommendation A). Although in all these pivotal clinical trials, lymphadenectomy was required as an inclusion criteria, the impact of avoiding a lymphadenectomy on the results of adjuvant treatment is unknown, leaving the decision whether or not performing it before in the context of a discussion with the patient (Level of evidence 3, grade of recommendation C). Finally, stage IIIA AJCC v7 patients were included in COMBI-AD and Keynote 054 trials with the inclusion criteria of sentinel lymph nodes $>1 \mathrm{~mm}$; regulatory approvals of FDA, EMA, and AEMPS admit to extend the use of adjuvant systemic treatment to with anti-PD-1 antibodies all stage III, including stage IIIA, but there is no clear evidence of its use in IIIA with $<1 \mathrm{~mm}$ (Level of evidence 3, grade of recommendation B-C). Selection of a specific agent depends largely on $B R A F$ mutation status and toxicity profiles (Level of evidence 3-4, grade of recommendation B). Figure 2 shows adjuvant treatment algorithm in high-risk melanoma.

For patients who relapse with metastatic disease after initial adjuvant therapy, options include treatment with an alternative active systemic therapy or inclusion in a clinical trial (Level of evidence 3, grade of recommendation C) [38]. 


\section{HIGH RISK ADJUVANT MELANOMA}

TREATMENT

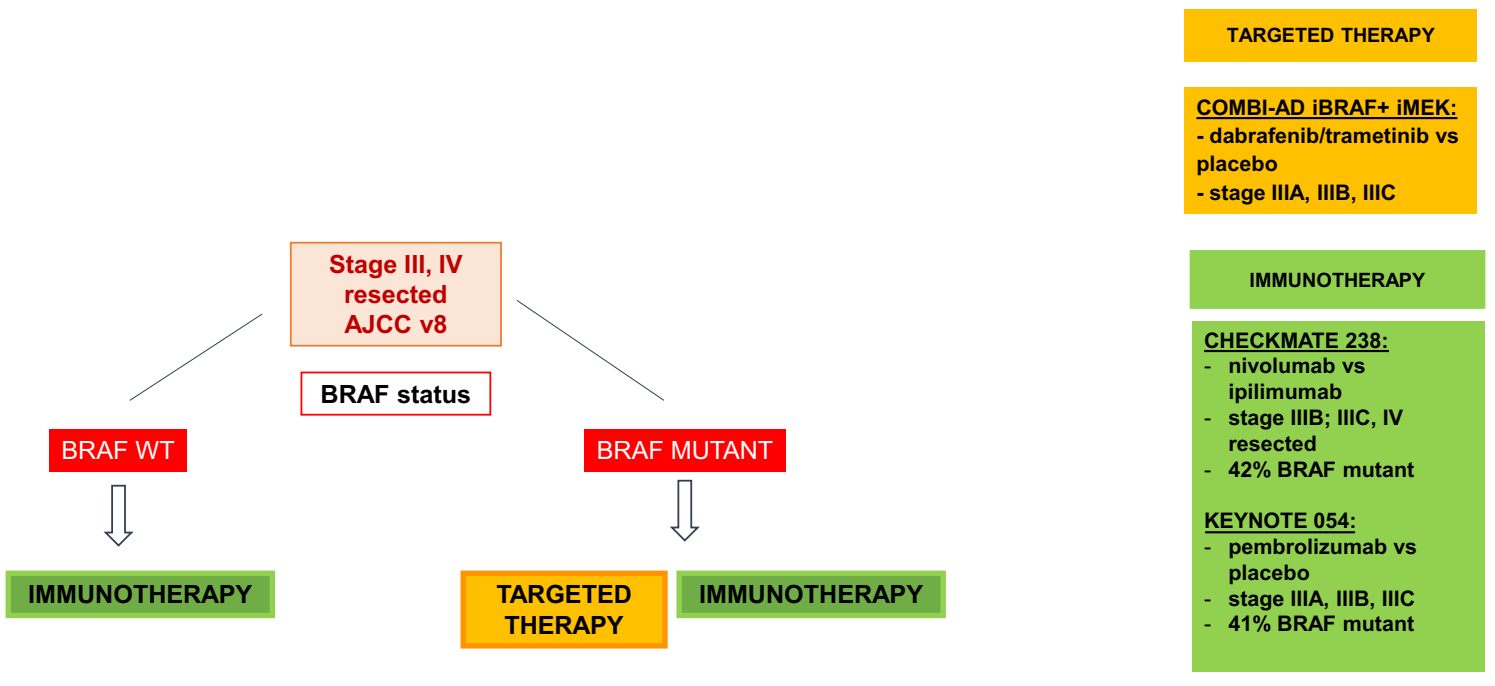

Fig. 2 Adjuvant treatment algorithm in high-risk melanoma

Table 2 Main characteristics of the pivotal trials of immunotherapy in advanced melanoma

\begin{tabular}{|c|c|c|c|c|}
\hline Treatment & Considerations & $\begin{array}{l}\text { PFS (median } \\
\text { months 95\% IC) }\end{array}$ & OS (median months, 95\% IC) & Update overall survival (\%) \\
\hline $\begin{array}{l}\text { Nivolumab }[3,4] \\
\text { CheckMate } 066\end{array}$ & $\begin{array}{l}\text { BRAF WT patients } \\
\text { Control arm: DTIC } \\
\text { Protocol amendment: cross } \\
\text { over nivolumab }\end{array}$ & $5.1(3.5-10.8)$ & $\begin{array}{l}\text { NR (survival rate at } 1 \text { year } \\
72.9 \%(65.5-78.9)\end{array}$ & $51.2 \%$ at 3 years \\
\hline $\begin{array}{l}\text { Pembrolizumab }[5,6] \\
\text { KEYNOTE-006 }\end{array}$ & $\begin{array}{l}\text { Control arm: ipilimumab } \\
34 \% \text { second-line treatment } \\
36 \% \text { BRAF mutant }\end{array}$ & $4.1(2.9 \text { a } 6.9)^{*}$ & $\begin{array}{l}\text { NR (survival rate at } 1 \text { year } \\
68.4 \% \text { ) }\end{array}$ & $32.7(24.5-41.6)$ at 5 years** \\
\hline $\begin{array}{l}\text { Ipilimumab + nivolumab } \\
{[7,8]} \\
\text { CheckMate } 067\end{array}$ & $\begin{array}{l}\text { Control arm: ipilimumab } \\
31.5 \% \text { BRAF mutant }\end{array}$ & $11.5(8.9-16.7)$ & $64 \%$ survival rate at 2 years & $58 \%$ at 3 years; $52 \%$ at 5 years \\
\hline
\end{tabular}

$N R$ not reached, $N C$ unknown

*At dose $10 \mathrm{mg} / \mathrm{kg}$ every 3 weeks

**Combined pembrolizumab groups

\section{Treatment of advanced disease}

\section{Oligometastatic disease}

Some stage IV patients present with a resectable, oligometastatic disease and surgical excision or stereotactic radiosurgery (SRS) of solitary metastases should be considered whenever feasible. One-third of patients with resected metastasis may become long-term survivors (Level of evidence $2 b$, grade of recommendation B) [39]. Surgery may be the preferred option for selected patients if feasible, preferentially combined with adjuvant systemic therapies as previously commented.

\section{Systemic treatment of unresectable advanced $/ \mathrm{m} 1$ disease}

\section{Treatment options in first line}

Immunotherapy Immunotherapy based on immune checkpoint inhibitors has demonstrated its superiority over chemotherapy in terms of response, PFS and OS in first-line treatment (Level of evidence 1, grade of recommendation A). This option, unlike that occurs with targeted therapy against BRAF, is not based on any biomarker such as the expression of the programmed death-ligand 1 (PD-L1) (Level of evidence I, grade of recommendation $\mathrm{B}$ ) or tumor mutational 
Table 3 Randomized trials with of BRAF and MEK inhibitors in advanced BRAF mutant melanoma

\begin{tabular}{lllll}
\hline Combination & $\begin{array}{l}\text { Progression-free survival } \\
\text { (median months, 95\% IC) }\end{array}$ & $\begin{array}{l}\text { Overall survival (median } \\
\text { months, 95\% IC) }\end{array}$ & $\begin{array}{l}\text { Patients alive at 3, 4, and } \\
\text { 5 years }(\%)\end{array}$ \\
\hline Dabrafenib + trametinib & $11.1(9.5-12.8)$ & $25.9(22.6-31.5)$ & $44,37,34$ & References \\
Vemurafenib + cobimetinib & $12.6(9.5-14.7)$ & $22.5(20.3-28.8)$ & $38.5,34.7$, NA \\
Encorafenib + binimetinib & $14.9(11.0-20.2)$ & $33.6(24.4-39.2)$ & 47,39, NA & {$[1]$} \\
\hline
\end{tabular}

burden (TMB) (Level of evidence IV, grade of recommendation C). Ipilimumab, an anti-CTLA-4 (cytotoxic T-lymphocyte-associated protein 4) antibody, was the first treatment to show an improvement in overall survival in patients with metastatic melanoma [40, 41]. This option has been exchanged in favor to PD-1 inhibitors such as nivolumab $[42,43]$, pembrolizumab $[44,45]$, or the combination of ipilimumab plus nivolumab [46, 47]. Table 2 summarizes the main characteristics of the pivotal trials of immunotherapy in advanced melanoma.

The clinical criteria that can help us to choose the best first-line treatment option with immune checkpoint inhibitors (monotherapy or combination) or the duration of treatment are not yet established. Different studies have proposed several clinical markers such as LDH (lactate dehydrogenase), lymphocytes, leukocytes, or eosinophils count that could predict the response to ICI, but data are inconclusive (Level of evidence IV, grade of recommendation C) [48].

On the other hand, there is other type of immunotherapy such as Talimogene Laherparepvec, an intralesional virotherapy that has shown an improvement in durable response rate, overall survival, and loco-regional control respect to GM-CSF in patients with injectable lesions and unresectable stage IIIB-C or IV melanoma, specially when used as first-line therapy (Level of evidence 1, grade of recommendation B) [49].

Targeted therapy Currently, there are three different combinations of BRAF and MEK inhibitors based in four randomized phase III clinical trials that improve both progression-free survival and overall survival in comparison with BRAF inhibitors alone (Table 3) [50, 51]. The combination of BRAF and MEK inhibitors should be the therapy of choice when targeted therapy is considered, unless absolute contraindication for MEK inhibitors is present (Level of evidence 1, grade of recommendation A).

There are certain subgroups that of poor prognosis, being the most important factors an elevated LDH, ECOG $>1$ and high tumor burden (expressed in number of organs involved) [50, 52]. However, a combination of BRAF and MEK inhibitor would be the first option over monotherapy (Level of evidence 2, grade of recommendation B).
Direct comparison among the three different combos does not exist, and similar efficacy with small differences in the toxicity profile has been described. When selecting the combination, patient preferences, drug availability, and efficiency criteria should be taken into account (Level of evidence 4 , grade of recommendation C).

First-line selection in BRAFm The best treatment sequence for BRAF mutant patients is unknown, since no direct comparison exists. First-line decision between targeted therapies or immunotherapy is currently being studied in prospective trials (SECOMBIT, NCT02631447) to define the best sequencing combination treatment in terms of OS, the primary efficacy variable. Meanwhile, the decision should be based on patient's profile (comorbidities, ECOG, symptoms, and life expectancy) and on melanoma characteristics (tumor burden, site of metastasis, and level of LDH) [52, 53] (Level of evidence 2, grade of recommendation B).

Most studies have demonstrated a higher number of events during the first 12 months with immunotherapy than with targeted therapy and, by contrast, patients with immunotherapy have better survival beyond the first year [50, 54]. With all the aforementioned, it can be advised that in those patients where the first months of treatment can be administered safely (for example, those who will not progress quickly, or where immediate response is not required due to involvement of an organ or its function) would be good candidates for immunotherapy, reserving targeted therapy for later lines (Level of evidence 2, grade of recommendation B).

\section{Treatment options in second line}

Treatment options in second line depend on the treatment administered in the first line, as well as, on the mutational status. For the BRAF wild-type patients, options for a second-line treatment are limited, and inclusion in clinical trials is a priority. When the first line was an anti-PD-1 antibody, ipilimumab (Level of evidence 2, grade of recommendation B) and the combination of nivolumab and ipilimumab (Level of evidence 4, grade of recommendation B) are two valid options [55]. Finally, chemotherapy (Dacarbazine and Temozolomide) can be considered for patients who 
exhausted other options (Level of evidence 2, grade of recommendation D).

In the BRAF mutant population treated with an anti-PD-1 antibody in first line, the combination of BRAF and MEK inhibitors is the preferred option. Although their activity has not been prospectively studied after progression to antiPD-1, it seems to be similar to the first line of treatment in terms of response (Level of evidence 2, grade of recommendation A) [56]. Data from the Columbus Study, where BRAF mutant patients may have previously received immunotherapy, showed that these patients also benefited from the combination (Level of evidence 2, grade of recommendation A) [57].

In the BRAF mutant population treated with the combination of BRAF and MEK inhibitors in first line, anti-PD-1 antibody and the combination of nivolumab and ipilimumab are valid options.

\section{Treatment beyond progression}

Treatment beyond progression might be an option in selected patients both on targeted as well as on immunotherapy based on retrospective data [58]. No randomized data are available at this time. Treatment beyond progression is generally not recommended unless there is a suspicion of pseudoprogression, bearing in mind that the analysis of these data is subject to many biases related to patient status.

\section{Management of brain metastasis}

It is estimated that up to $50-60 \%$ of metastatic melanoma patients will develop brain metastasis. First, a stepwise and multidisciplinary approach is highly recommended to design an individualized plan for every patient (Level of evidence 4, grade of recommendation A) [59]. In an effort to classify patients into similar prognostic groups, some key clinical factors such as Karnofsky Performance Score (KPS), number of brain metastases, extracranial metastases, age, and BRAF status constitute the basis of the specific graded prognostic assessment (GPA) index for melanoma (Melanoma-mol GPA) [60] and could be extremely helpful to guide clinical decision-making (Level of evidence 3, grade of recommendation B).

Among locoregional strategies, surgery must be considered to treat symptomatic and large brain metastasis, especially in the case of solitary brain metastasis and when a pathological and/or molecular diagnosis is needed (Level of evidence 4, grade of recommendation B) [61]. SRS is generally recommended in patients with 1-4 brain metastases with less than 3-4 cm (Level of evidence 3, grade of recommendation A), although the role of SRS has been tested for up to 15 brain metastasis [61]. Adjuvant SRS yields the same overall survival but with fewer declines in cognitive function, so SRS on the surgical cavity and not WBRT is recommended after excision of brain metastases (Level of evidence 1b, grade of recommendation A) [62]. Whole brain radiation therapy (WBRT) is discouraged except in the palliative setting when other options are not feasible (Level of evidence 4, grade of recommendation C) [59].

When locoregional strategies are discarded, systemic therapies must be considered. At this point, two main clinical situations emerge. In asymptomatic, previously untreated brain metastasis patients, combination immunotherapy with nivolumab and ipilimumab has demonstrated outstanding results with intracranial response rates ranging from 46 to 57\% and median PFS and DOR not reached with a median follow-up of 20.6 months [63]. Pembrolizumab, nivolumab, and ipilimumab as single therapies also show some degree of activity (ORR around 20\%) [64]. In BRAF mutant patients, BRAF and MEK inhibitors obtain high intracranial responses, which rises up to $58 \%$ with the combination of dabrafenib and trametinib [65]. However, these responses seem to be shorter than those obtained in extracranial sites. Aforementioned results make reasonable advising nivolumab plus ipilimumab as the preferred firstline treatment for patients with asymptomatic brain metastasis not amenable to surgery or SRS, irrespective of BRAF status, whenever possible (Level of evidence 3, grade of recommendation A). In BRAF-mutated patients, combination of BRAF and MEK inhibitors remains a good alternative option in first and second lines (Level of evidence 3, grade of recommendation $\mathrm{B}$ ).

Unfortunately, symptomatic and/or previously treated patients obtain poorer results, especially with immunotherapy, and new approaches are eagerly needed in this setting [59].

\section{Follow-up}

On average, $20-30 \%$ of early stage melanoma patients will develop a recurrence within 5 years [66]. For stage I-II melanomas, recurrences will be in $50 \%$ of cases at regional lymph nodes, $30 \%$ as distant metastasis and $20 \%$ will be local relapses or in-transit metastasis. For stage III melanoma, up to $95 \%$ occur during the first 3 years of follow-up [66], and up to $50 \%$ will be distant recurrences, $25 \%$ regional and $25 \%$ local relapses. About $2-10 \%$ will have a second primary melanoma, most of them during the first year after initial diagnosis [67]. 
Self-examination is an essential component of the followup and can lead to early recognition of recurrences and new melanomas [68]. Patients should receive instructions on selfexamination (Level of evidence 3, grade of recommendation B). Over the last few years, several skin cancer detection applications for smartphones have been developed through analysis of artificial intelligence algorithms. Further studies are needed before implementing these techniques in the general population (Level of evidence 4, grade of recommendation C).

Physical examination has proven to be an effective procedure for early recurrence detection [68] and should be performed in all melanoma patients during follow-up (Level of evidence 2, grade of recommendation A). Physical exam must include skin and nodes exam. Total body photography, sequential digital dermatoscopy imaging, and reflectance confocal microscopy, must be helpful in patients with a high number of moles or presence of clinical atypical nevi (Level of evidence 3, grade of recommendation A). For stage I-IIA melanomas, the frequency of physical exams should be, at least, annually, life-long, but it depends on the risk factors of each patient (Level of evidence 3, grade of recommendation A). For patients with stage IIB-IV melanomas, physical examinations should be performed every 3-6 months during the first 2 years, and then every 3-6 months for 3 years, and after 5 years, they could be done annually (Level of evidence 3 , grade of recommendation A).

Routine blood testing is optional, as few recurrences are detected by increased LDH and S-100 levels [68] (Level of evidence 4, grade of recommendation C). Liquid biopsy for melanoma screening using the determination of BRAF mutation in cfDNA from blood or other body fluids is a promising technique, but it is not routinely indicated yet (Level of evidence 4, grade of recommendation C).

Lymph-node sonography has proven to be the most sensitive and most specific procedure for the detection of locoregional lymph-node metastases [69]. In patients with stage IIC-III melanomas, lymph-node sonography of regional areas must be performed regularly, and it should be performed every 4 months during the first 2 years, and every 6 months during the next 3 years, especially in patients with positive sentinel lymph nodes without lymphnode dissection (Grade of recommendation A; level of evidence 1).

General recommendation about imaging procedures is not possible, since no prospective studies have assessed if early recurrence detection impacts in the overall survival. Some studies in IIC-III melanoma patients have demonstrated that an extensive follow-up including CT body scan and brain MRI detects almost $50 \%$, and $8 \%$ of recurrences [70, 71], so imaging follow up every 3 months is recommended (Grade of recommendation B; level of evidence 3). Routine follow-up with PET-CT is not recommended, although some studies have demonstrated a higher sensitivity for detecting distant metastases in the extremities (Grade of recommendation C; level of evidence 4) [72]. For earlier stages I-IIA where the risk of relapse is lower, radiological follow-up with body CT scan and brain MRI is optional (Grade of recommendation $\mathrm{C}$; level of evidence 4 ).

\section{Summary of recommendations and evidence}

\begin{tabular}{|c|c|c|}
\hline & $\begin{array}{l}\text { Level of } \\
\text { evidence }\end{array}$ & $\begin{array}{l}\text { Grade of } \\
\text { recommen- } \\
\text { dation }\end{array}$ \\
\hline $\begin{array}{l}\text { Physical protection and regular use of sun- } \\
\text { screen reduce the incidence of cutaneous } \\
\text { melanoma }\end{array}$ & 1 & A \\
\hline Diagnosis and pathology & $1 b$ & A \\
\hline \multicolumn{3}{|l|}{$\begin{array}{l}\text { Dermatoscopy by an experienced physi- } \\
\text { cian is recommended for the diagnosis of } \\
\text { pigmented lesions }\end{array}$} \\
\hline $\begin{array}{l}\text { Whole-body photography and digital } \\
\text { dermatoscopy are useful in people at high } \\
\text { risk of melanoma, especially in early } \\
\text { diagnosis }\end{array}$ & $2 b$ & $\mathrm{~B}$ \\
\hline $\begin{array}{l}\text { Determination of BRAF V600 status is } \\
\text { mandatory in patients with resectable or } \\
\text { unresectable stage III or IV melanoma }\end{array}$ & 1 & A \\
\hline \multicolumn{3}{|l|}{ Staging } \\
\hline $\begin{array}{l}\text { In pT1b-pT4b melanoma, US for locore- } \\
\text { gional LN metastasis, CT or PET-TC and } \\
\text { brain MRI, is recommended }\end{array}$ & 3 & A \\
\hline \multicolumn{3}{|l|}{ Treatment of primary tumor } \\
\hline $\begin{array}{l}\text { Excisional biopsy is recommended on all } \\
\text { suspicious lesions }\end{array}$ & $1 \mathrm{a}$ & A \\
\hline $\begin{array}{l}\text { Safety surgical margins should be Breslow- } \\
\text { adapted }\end{array}$ & $1 b$ & A \\
\hline $\begin{array}{l}\text { SLN is indicated if Breslow }>0.8 \mathrm{~mm} \\
\text { or }<0.8 \mathrm{~mm} \text { with ulceration }\end{array}$ & $2 \mathrm{a}$ & A \\
\hline $\begin{array}{l}\text { Routine CLND is not recommended for } \\
\text { SLN + patients }\end{array}$ & $1 b$ & A \\
\hline $\begin{array}{l}\text { CLND is recommended for clinically } \\
\text { detected regional lymph nodes }\end{array}$ & 4 & $\mathrm{C}$ \\
\hline \multicolumn{3}{|l|}{ Adjuvant therapy } \\
\hline $\begin{array}{l}\text { Adjuvant radiotherapy is not recommended, } \\
\text { but it may be considered for selected cases }\end{array}$ & $2 b$ & $\mathrm{~B}$ \\
\hline $\begin{array}{l}\text { Adjuvant anti-PD- } 1 \text { treatment with } \\
\text { nivolumab and pembrolizumab or targeted } \\
\text { therapies with dabrafenib and trametinib } \\
\text { are recommended in resected stage III-IV } \\
\text { melanoma }\end{array}$ & 1 & A \\
\hline \multicolumn{3}{|l|}{ Oligometastatic disease } \\
\hline $\begin{array}{l}\text { Surgical excision or SRS of solitary metas- } \\
\text { tases should be considered }\end{array}$ & $2 b$ & $\mathrm{~B}$ \\
\hline \multicolumn{3}{|l|}{ Management of advanced disease } \\
\hline First line advanced/M1 disease & & \\
\hline
\end{tabular}




\begin{tabular}{|c|c|c|}
\hline & $\begin{array}{l}\text { Level of } \\
\text { evidence }\end{array}$ & $\begin{array}{l}\text { Grade of } \\
\text { recommen- } \\
\text { dation }\end{array}$ \\
\hline $\begin{array}{l}\text { Anti-PD-1 treatment (nivolumab or } \\
\text { pembrolizumab) or ipilimumab and } \\
\text { nivolumab are a standard of care for all } \\
\text { patients with advanced melanoma }\end{array}$ & 1 & A \\
\hline $\begin{array}{l}\text { Intralesional T-VEC is also an option for } \\
\text { unresectable stage IIIB-C or IV }\end{array}$ & 1 & $\mathrm{C}$ \\
\hline $\begin{array}{l}\text { In BRAF V600 melanoma, BRAF and } \\
\text { MEK inhibitors (dabrafenib-trametinib, } \\
\text { vemurafenib-cobimetinib, encorafenib- } \\
\text { binimetinib) are additional first-line } \\
\text { options }\end{array}$ & 1 & A \\
\hline \multicolumn{3}{|l|}{$\begin{array}{l}\text { Second line and beyond advanced/M1 } \\
\text { disease }\end{array}$} \\
\hline $\begin{array}{l}\text { In BRAF wild-type melanoma, } \\
\text { ipilimumab and the combination of } \\
\text { nivolumab and ipilimumab are two valid } \\
\text { options after an anti-PD-1 treatment }\end{array}$ & 2,4 & $\mathrm{~B}$ \\
\hline $\begin{array}{l}\text { In BRAFV600 melanoma, BRAF and } \\
\text { MEK inhibitors are the preferred option } \\
\text { after an anti-PD-1 treatment }\end{array}$ & 2 & A \\
\hline $\begin{array}{l}\text { In BRAFV600 melanoma treated with } \\
\text { BRAF and MEK inhibitors in first } \\
\text { line, anti-PD-1 treatment (nivolumab } \\
\text { or pembrolizumab) or ipilimumab and } \\
\text { nivolumab are valid options }\end{array}$ & 2 & A \\
\hline $\begin{array}{l}\text { Chemotherapy can be considered for } \\
\text { patients who exhausted other options }\end{array}$ & 2 & $\mathrm{D}$ \\
\hline \multicolumn{3}{|l|}{ Brain metastases } \\
\hline $\begin{array}{l}\text { Multidisciplinary approach is highly recom- } \\
\text { mended }\end{array}$ & 4 & A \\
\hline $\begin{array}{l}\text { Melanoma-mol GPA index could help to } \\
\text { guide clinical decision }\end{array}$ & 3 & $\mathrm{~B}$ \\
\hline $\begin{array}{l}\text { Surgery must be considered in sympto- } \\
\text { matic, large BM specially in solitary BM }\end{array}$ & 4 & $\mathrm{~B}$ \\
\hline $\begin{array}{l}\text { SRS is recommended in 1-4 BM metasta- } \\
\text { ses with less than } 3-4 \mathrm{~cm}\end{array}$ & 3 & A \\
\hline \multicolumn{3}{|l|}{ Follow-up } \\
\hline $\begin{array}{l}\text { Self-examination is recommended in all } \\
\text { patients }\end{array}$ & 3 & $\mathrm{~B}$ \\
\hline $\begin{array}{l}\text { Physical examinations is recommended in } \\
\text { all patients }\end{array}$ & 2 & A \\
\hline Routine blood testing is optional & 4 & $\mathrm{C}$ \\
\hline $\begin{array}{l}\text { Follow-up with CT body scan and brain } \\
\text { MRI in stages IIB-IV is recommended }\end{array}$ & 3 & $\mathrm{~B}$ \\
\hline $\begin{array}{l}\text { Follow-up with CT body scan and brain } \\
\text { MRI in stages I-IIA is optional }\end{array}$ & 4 & $\mathrm{C}$ \\
\hline $\begin{array}{l}\text { Lymph-node US is recommended in SLN- } \\
\text { positive patients }\end{array}$ & 1 & A \\
\hline
\end{tabular}

$S L N$ sentinel lymph node, $C L N D$ complete lymph-node resection, $S R S$ stereotactic radiosurgery, $B M$ brain metastasis

\section{Compliance with ethical standards}

Conflict of interest MMT reports grants and personal fees from BMS; personal fees from Astra Zeneca, Novartis, Roche, MSD, Boehringer Ingelheim, Takeda, Pierre-Fabre and Bayer; non-financial support from Astra Zeneca, MSD, Boehringer Ingelheim outside the submitted work. JLM reports personal fees from Novartis, Roche, Pierre-Fabre, BMS, MSD and grants from; Merck, Roche, Abbvie, Astra Zeneca outside the submitted work. I.M.-R. has received grants as advisory board member and travel and congress accommodation from BMS, MSD, Roche, Novartis, Amgen, Pierre Fabre, Merck Serono, Sanofi, Regeneron, Incyte, AstraZeneca, and Bioncotech. LCM reports grants and personal fees from BMS, Roche, MSD-Merck, and Amgen, personal fees from Pierre Fabre, Novartis, and grants from Celgene, outside the submitted work. EE reports personal fees from BMS, MSD, Novartis, Pierre Fabre, and Roche. MGC reports personal fees from NOVARTIS, BMS, and Roche. AB reports personal fees and non-financial support from BMS, MSD, Roche, Novartis, Sanofi, and Merck-Pfizer, and personal fees from Pierre Fabre and Incyte, outside the submitted work. KM, EPR, and EMC have nothing to disclose.

Ethical approval The current study has been performed in accordance with the ethical standards laid down in the 1964 Declaration of Helsinki and its later amendments.

Informed consent Not applicable.

Open Access This article is licensed under a Creative Commons Attribution 4.0 International License, which permits use, sharing, adaptation, distribution and reproduction in any medium or format, as long as you give appropriate credit to the original author(s) and the source, provide a link to the Creative Commons licence, and indicate if changes were made. The images or other third party material in this article are included in the article's Creative Commons licence, unless indicated otherwise in a credit line to the material. If material is not included in the article's Creative Commons licence and your intended use is not permitted by statutory regulation or exceeds the permitted use, you will need to obtain permission directly from the copyright holder. To view a copy of this licence, visit http://creativecommons.org/licenses/by/4.0/.

\section{References}

1. Shekelle PG, Woolf SH, Eccles M, Grimshaw J. Developing clinical guidelines. West J Med. 1999;170(6):348-51.

2. Dykewicz CA. Guidelines for preventing opportunistic infections among hematopoietic stem cell transplant recipients: focus on community respiratory virus infections. Biol Blood Marrow Transpl. 2001;7(Suppl):19S-22S.

3. Garbe C, Amaral T, Peris K, Hauschild A, Arenberger P, Bastholt $\mathrm{L}$, et al. European consensus-based interdisciplinary guideline for melanoma. Part 1: diagnostics-update 2019. Eur J Cancer (Oxford, England: 1990). 2020;126:141-58.

4. Whiteman DC, Green AC, Olsen CM. The Growing Burden of Invasive Melanoma: projections of incidence rates and numbers of new cases in six susceptible populations through 2031. J Invest Dermatol. 2016;136(6):1161-71.

5. Gutierrez-Gonzalez E, Lopez-Abente G, Aragones N, Pollan M, Pastor-Barriuso R, Sanchez MJ, et al. Trends in mortality from cutaneous malignant melanoma in Spain (1982-2016): sex-specific age-cohort-period effects. J Eur Acad Dermatol Venereol. 2019;33(8):1522-8. 
6. Rubio-Casadevall J, Puig-Vives M, Puigdemont M, Vilardell L, Carbo-Bague A, Marcos-Gragera R, et al. Patterns of increased incidence and survival of cutaneous melanoma in Girona (Spain) 1994-2013: a population-based study. Clin Transl Oncol Off Publ Fed Span Oncol Soc Natl Cancer Inst Mexico. 2018;20(12):1617-25.

7. Cifras del cancer en España. 2020. https://seom.org/dmcancer/ cifras-del-cancer/.

8. Elwood JM, Jopson J. Melanoma and sun exposure: an overview of published studies. Int J Cancer. 1997;73(2):198-203.

9. Gandini S, Sera F, Cattaruzza MS, Pasquini P, Zanetti R, Masini C, et al. Meta-analysis of risk factors for cutaneous melanoma: III. Family history, actinic damage and phenotypic factors. Eur J Cancer (Oxford, England: 1990). 2005;41(14):2040-59.

10. Gandini S, Sera F, Cattaruzza MS, Pasquini P, Abeni D, Boyle $\mathrm{P}$, et al. Meta-analysis of risk factors for cutaneous melanoma: Common and atypical naevi. Eur J Cancer (Oxford, England: 1990). 2005;41(1):28-44.

11. Toussi A, Mans N, Welborn J, Kiuru M. Germline mutations predisposing to melanoma. J Cutan Pathol. 2020;47(7):606-16.

12. Green AC, Williams GM, Logan V, Strutton GM. Reduced melanoma after regular sunscreen use: randomized trial follow-up. J Clin Oncol. 2011;29(3):257-63.

13. Grob JJ, Bonerandi JJ. The 'ugly duckling' sign: identification of the common characteristics of nevi in an individual as a basis for melanoma screening. Arch Dermatol. 1998;134(1):103-4.

14. Kittler H, Pehamberger H, Wolff K, Binder M. Diagnostic accuracy of dermoscopy. Lancet Oncol. 2002;3(3):159-65.

15. Lallas A, Apalla Z, Kyrgidis A, Papageorgiou C, Boukovinas I, Bobos M, et al. Second primary melanomas in a cohort of 977 melanoma patients within the first 5 years of monitoring. J Am Acad Dermatol. 2020;82(2):398-406.

16. Dinnes J, Deeks JJ, Saleh D, Chuchu N, Bayliss SE, Patel L, et al. Reflectance confocal microscopy for diagnosing cutaneous melanoma in adults. Cochrane Database Syst Rev. 2018;12:CD013190.

17. Gershenwald JE, Scolyer RA, Hess KR, Sondak VK, Long GV, Ross MI, et al. Melanoma staging: Evidence-based changes in the American Joint Committee on Cancer eighth edition cancer staging manual. CA Cancer J Clin. 2017;67(6):472-92.

18. Yao Z, Yaeger R, Rodrik-Outmezguine VS, Tao A, Torres NM, Chang MT, et al. Tumours with class 3 BRAF mutants are sensitive to the inhibition of activated RAS. Nature. 2017;548(7666):234-8.

19. Meng D, Carvajal RD. KIT as an oncogenic driver in melanoma: an update on clinical development. Am J Clin Dermatol. 2019;20(3):315-23.

20. Cirenajwis H, Lauss M, Ekedahl H, Torngren T, Kvist A, Saal LH, et al. NF1-mutated melanoma tumors harbor distinct clinical and biological characteristics. Mol Oncol. 2017;11(4):438-51.

21. Hayes AJ, Maynard L, Coombes G, Newton-Bishop J, Timmons M, Cook M, et al. Wide versus narrow excision margins for highrisk, primary cutaneous melanomas: long-term follow-up of survival in a randomised trial. Lancet Oncol. 2016;17(2):184-92.

22. Balch CM, Gershenwald JE, Soong SJ, Thompson JF, Ding S, Byrd DR, et al. Multivariate analysis of prognostic factors among 2,313 patients with stage III melanoma: comparison of nodal micrometastases versus macrometastases. J Clin Oncol. 2010;28(14):2452-9.

23. Nguyen CL, McClay EF, Cole DJ, O’Brien PH, Gillanders WE, Metcalf JS, et al. Melanoma thickness and histology predict sentinel lymph node status. Am J Surg. 2001;181(1):8-11.

24. Han D, Zager JS, Shyr Y, Chen H, Berry LD, Iyengar S, et al. Clinicopathologic predictors of sentinel lymph node metastasis in thin melanoma. J Clin Oncol. 2013;31(35):4387-93.
25. Leiter U, Stadler R, Mauch C, Hohenberger W, Brockmeyer N, Berking C, et al. Complete lymph node dissection versus no dissection in patients with sentinel lymph node biopsy positive melanoma (DeCOG-SLT): a multicentre, randomised, phase 3 trial. Lancet Oncol. 2016;17(6):757-67.

26. Faries MB, Thompson JF, Cochran AJ, Andtbacka RH, Mozzillo N, Zager JS, et al. Completion dissection or observation for sentinel-node metastasis in melanoma. N Engl J Med. 2017;376(23):2211-22.

27. Morton DL, Wanek L, Nizze JA, Elashoff RM, Wong JH. Improved long-term survival after lymphadenectomy of melanoma metastatic to regional nodes. Analysis of prognostic factors in 1134 patients from the John Wayne Cancer Clinic. Ann Surg. 1991;214(4):491-9 (discussion 9-501).

28. Strom T, Torres-Roca JF, Parekh A, Naghavi AO, Caudell JJ, Oliver DE, et al. Regional radiation therapy impacts outcome for node-positive cutaneous melanoma. J Natl Compr Canc Netw. 2017;15(4):473-82.

29. Henderson MA, Burmeister BH, Ainslie J, Fisher R, Di Iulio J, Smithers BM, et al. Adjuvant lymph-node field radiotherapy versus observation only in patients with melanoma at high risk of further lymph-node field relapse after lymphadenectomy (ANZMTG 01.02/TROG 02.01): 6-year follow-up of a phase 3, randomised controlled trial. Lancet Oncol. 2015;16(9):1049-60.

30. Weber J, Mandala M, Del Vecchio M, Gogas HJ, Arance AM, Cowey CL, et al. Adjuvant Nivolumab versus Ipilimumab in resected stage III or IV Melanoma. N Engl J Med. 2017;377(19):1824-35.

31. Ascierto PA, Del Vecchio M, Mandala M, Gogas H, Arance AM, Dalle $\mathrm{S}$, et al. Adjuvant nivolumab versus ipilimumab in resected stage IIIB-C and stage IV melanoma (CheckMate 238): 4-year results from a multicentre, double-blind, randomised, controlled, phase 3 trial. Lancet Oncol. 2020;21(11):1465-77.

32. Eggermont AMM, Blank CU, Mandala M, Long GV, Atkinson VG, Dalle $S$, et al. Longer follow-up confirms recurrence-free survival benefit of adjuvant pembrolizumab in high-risk stage III Melanoma: Updated results from the EORTC 1325-MG/KEYNOTE-054 trial. J Clin Oncol. 2020;38(33):3925-36.

33. Eggermont AMM, Blank CU, Mandala M, Long GV, Atkinson V, Dalle S, et al. Adjuvant Pembrolizumab versus placebo in resected stage III Melanoma. N Engl J Med. 2018;378(19):1789-801.

34. Long GV, Hauschild A, Santinami M, Atkinson V, Mandala M, Chiarion-Sileni V, et al. Adjuvant dabrafenib plus trametinib in stage III BRAF-mutated Melanoma. N Engl J Med. 2017;377(19):1813-23.

35. Hauschild A, Dummer R, Schadendorf D, Santinami M, Atkinson V, Mandala M, et al. Longer follow-up confirms relapse-free survival benefit with adjuvant dabrafenib plus trametinib in patients with resected BRAF V600-Mutant stage III Melanoma. J Clin Oncol. 2018;36(35):3441-9.

36. Dummer R, Brase JC, Garrett J, Campbell CD, Gasal E, Squires $\mathrm{M}$, et al. Adjuvant dabrafenib plus trametinib versus placebo in patients with resected, BRAF(V600)-mutant, stage III melanoma (COMBI-AD): exploratory biomarker analyses from a randomised, phase 3 trial. Lancet Oncol. 2020;21(3):358-72.

37. Dummer R, Hauschild A, Santinami M, Atkinson V, Mandala M, Kirkwood JM, et al. Five-year analysis of adjuvant Dabrafenib plus Trametinib in stage III Melanoma. N Engl J Med. 2020;383(12):1139-48.

38. Owen CN, Shoushtari AN, Chauhan D, Palmieri DJ, Lee B, Rohaan MW, et al. Management of early melanoma recurrence despite adjuvant anti-PD-1 antibody therapy(). Ann Oncol Off J Eur Soc Med Oncol. 2020;31(8):1075-82.

39. Sosman JA, Moon J, Tuthill RJ, Warneke JA, Vetto JT, Redman BG, et al. A phase 2 trial of complete resection for stage IV 
melanoma: results of Southwest Oncology Group Clinical Trial S9430. Cancer. 2011;117(20):4740-6.

40. Robert C, Thomas L, Bondarenko I, O’Day S, Weber J, Garbe $\mathrm{C}$, et al. Ipilimumab plus dacarbazine for previously untreated metastatic melanoma. N Engl J Med. 2011;364(26):2517-26.

41. Ascierto PA, Del Vecchio M, Robert C, Mackiewicz A, Chiarion-Sileni V, Arance A, et al. Ipilimumab $10 \mathrm{mg} / \mathrm{kg}$ versus ipilimumab $3 \mathrm{mg} / \mathrm{kg}$ in patients with unresectable or metastatic melanoma: a randomised, double-blind, multicentre, phase 3 trial. Lancet Oncol. 2017;18(5):611-22.

42. Ascierto PA, Long GV, Robert C, Brady B, Dutriaux C, Di Giacomo AM, et al. Survival outcomes in patients with previously untreated BRAF wild-type advanced melanoma treated with nivolumab therapy: three-year follow-up of a randomized phase 3 trial. JAMA Oncol. 2019;5(2):187-94.

43. Robert C, Long GV, Brady B, Dutriaux C, Maio M, Mortier $\mathrm{L}$, et al. Nivolumab in previously untreated melanoma without BRAF mutation. N Engl J Med. 2015;372(4):320-30.

44. Schachter J, Ribas A, Long GV, Arance A, Grob JJ, Mortier L, et al. Pembrolizumab versus ipilimumab for advanced melanoma: final overall survival results of a multicentre, randomised, open-label phase 3 study (KEYNOTE-006). Lancet. 2017;390(10105):1853-62.

45. Robert C, Ribas A, Schachter J, Arance A, Grob JJ, Mortier L, et al. Pembrolizumab versus ipilimumab in advanced melanoma (KEYNOTE-006): post hoc 5-year results from an open-label, multicentre, randomised, controlled, phase 3 study. Lancet Oncol. 2019;20(9):1239-51.

46. Larkin J, Hodi FS, Wolchok JD. Combined Nivolumab and Ipilimumab or Monotherapy in Untreated Melanoma. N Engl J Med. 2015;373(13):1270-1.

47. Wolchok JD, Chiarion-Sileni V, Gonzalez R, Rutkowski P, Grob JJ, Cowey CL, et al. Overall survival with combined nivolumab and ipilimumab in advanced Melanoma. N Engl J Med. 2017;377(14):1345-56.

48. Espinosa E, Marquez-Rodas I, Soria A, Berrocal A, Manzano JL, Gonzalez-Cao M, et al. Predictive factors of response to immunotherapy-a review from the Spanish Melanoma Group (GEM). Ann Transl Med. 2017;5(19):389.

49. Andtbacka RH, Kaufman HL, Collichio F, Amatruda T, Senzer $\mathrm{N}$, Chesney J, et al. Talimogene laherparepvec improves durable response rate in patients with advanced melanoma. J Clin Oncol. 2015;33(25):2780-8.

50. Liszkay G, Gogas H, Mandalà M, Fernandez AMA, Garbe C, Schadendorf D, et al. Update on overall survival in COLUMBUS: a randomized phase III trial of encorafenib (ENCO) plus binimetinib (BINI) versus vemurafenib (VEM) or ENCO in patients with BRAF V600-mutant melanoma. J Clin Oncol. 2019;37(15_suppl):9512.

51. Dreno B, Ascierto PA, McArthur GA, Atkinson V, Liszkay G, Giacomo AMD, et al. Efficacy and safety of cobimetinib (C) combined with vemurafenib (V) in patients (pts) with BRAFV600 mutation-positive metastatic melanoma: analysis from the 4-year extended follow-up of the phase 3 coBRIM study. J Clin Oncol. 2018;36(15):9522.

52. Long GV, Grob JJ, Nathan P, Ribas A, Robert C, Schadendorf $\mathrm{D}$, et al. Factors predictive of response, disease progression, and overall survival after dabrafenib and trametinib combination treatment: a pooled analysis of individual patient data from randomised trials. Lancet Oncol. 2016;17(12):1743-54

53. Hauschild A, Larkin J, Ribas A, Dréno B, Flaherty KT, Ascierto $\mathrm{PA}$, et al. Modeled prognostic subgroups for survival and treatment outcomes in BRAF V600-mutated metastatic melanoma: pooled analysis of 4 randomized clinical trials. JAMA Oncol. 2018;4(10):1382-8.

54. Ugurel S, Röhmel J, Ascierto PA, Flaherty KT, Grob JJ, Hauschild A, et al. Survival of patients with advanced metastatic melanoma: the impact of novel therapies-update 2017. Eur J Cancer (Oxford, England : 1990). 2017;83:247-57.

55. Zimmer L, Apuri S, Eroglu Z, Kottschade LA, Forschner A, Gutzmer R, et al. Ipilimumab alone or in combination with nivolumab after progression on anti-PD-1 therapy in advanced melanoma. Eur J Cancer (Oxford, England: 1990). 2017;75:47-55.

56. Aya F, Fernandez-Martinez A, Gaba L, Victoria I, Tosca M, Pineda E, et al. Sequential treatment with immunotherapy and BRAF inhibitors in BRAF-mutant advanced melanoma. Clin Transl Oncol Off Publ Fed Span Oncol Soc Natl Cancer Inst Mexico. 2017;19(1):119-24.

57. Dummer R, Ascierto PA, Gogas HJ, Arance A, Mandala M, Liszkay $\mathrm{G}$, et al. Encorafenib plus binimetinib versus vemurafenib or encorafenib in patients with BRAF-mutant melanoma (COLUMBUS): a multicentre, open-label, randomised phase 3 trial. Lancet Oncol. 2018;19(5):603-15.

58. Beaver JA, Hazarika M, Mulkey F, Mushti S, Chen H, He K, et al. Patients with melanoma treated with an anti-PD-1 antibody beyond RECIST progression: a US Food and Drug Administration pooled analysis. Lancet Oncol. 2018;19(2):229-39.

59. Michielin O, van Akkooi ACJ, Ascierto PA, Dummer R, Keilholz U. Cutaneous melanoma: ESMO Clinical Practice Guidelines for diagnosis, treatment and follow-up $\dagger$. Ann Oncol Off J Eur Soc Med Oncol. 2019;30(12):1884-901.

60. Sperduto PW, Jiang W, Brown PD, Braunstein S, Sneed P, Wattson DA, et al. Estimating survival in melanoma patients with brain metastases: an update of the graded prognostic assessment for melanoma using molecular markers (Melanoma-molGPA). Int J Radiat Oncol Biol Phys. 2017;99(4):812-6.

61. Wasif N, Bagaria SP, Ray P, Morton DL. Does metastasectomy improve survival in patients with Stage IV melanoma? A cancer registry analysis of outcomes. J Surg Oncol. 2011;104(2):111-5.

62. Brown PD, Ballman KV, Cerhan JH, Anderson SK, Carrero XW, Whitton AC, et al. Postoperative stereotactic radiosurgery compared with whole brain radiotherapy for resected metastatic brain disease (NCCTG N107C/CEC.3): a multicentre, randomised, controlled, phase 3 trial. Lancet Oncol. 2017;18(8):1049-60.

63. Tawbi HA, Forsyth PA, Algazi A, Hamid O, Hodi FS, Moschos SJ, et al. Combined Nivolumab and Ipilimumab in Melanoma Metastatic to the Brain. N Engl J Med. 2018;379(8):722-30.

64. Rishi A, Yu HM. Current treatment of melanoma brain metastasis. Curr Treat Opt Oncol. 2020;21(6):45.

65. Davies MA, Saiag P, Robert C, Grob JJ, Flaherty KT, Arance A, et al. Dabrafenib plus trametinib in patients with BRAF(V600)mutant melanoma brain metastases (COMBI-MB): a multicentre, multicohort, open-label, phase 2 trial. Lancet Oncol. 2017;18(7):863-73.

66. Rockberg J, Amelio JM, Taylor A, Jorgensen L, Ragnhammar P, Hansson J. Epidemiology of cutaneous melanoma in SwedenStage-specific survival and rate of recurrence. Int J Cancer. 2016;139(12):2722-9.

67. Dicker TJ, Kavanagh GM, Herd RM, Ahmad T, McLaren KM, Chetty U, et al. A rational approach to melanoma follow-up in patients with primary cutaneous melanoma, Scottish Melanoma Group. Br J Dermatol. 1999;140(2):249-54.

68. Garbe C, Paul A, Kohler-Spath H, Ellwanger U, Stroebel W, Schwarz M, et al. Prospective evaluation of a follow-up schedule in cutaneous melanoma patients: recommendations for an effective follow-up strategy. J Clin Oncol. 2003;21(3):520-9. 
69. Xing Y, Bronstein Y, Ross MI, Askew RL, Lee JE, Gershenwald $\mathrm{JE}$, et al. Contemporary diagnostic imaging modalities for the staging and surveillance of melanoma patients: a meta-analysis. $\mathbf{J}$ Natl Cancer Inst. 2011;103(2):129-42.

70. Podlipnik S, Carrera C, Sanchez M, Arguis P, Olondo ML, Vilana $\mathrm{R}$, et al. Performance of diagnostic tests in an intensive follow-up protocol for patients with American Joint Committee on Cancer (AJCC) stage IIB, IIC, and III localized primary melanoma: a prospective cohort study. J Am Acad Dermatol. 2016;75(3):516-24.

71. Podlipnik S, Moreno-Ramirez D, Carrera C, Barreiro A, Manubens E, Ferrandiz-Pulido L, et al. Cost-effectiveness analysis of imaging strategy for an intensive follow-up of patients with
American Joint Committee on Cancer stage IIB, IIC and III malignant melanoma. Br J Dermatol. 2019;180(5):1190-7.

72. Schroer-Gunther MA, Wolff RF, Westwood ME, Scheibler FJ, Schurmann C, Baumert BG, et al. F-18-fluoro-2-deoxyglucose positron emission tomography (PET) and PET/computed tomography imaging in primary staging of patients with malignant melanoma: a systematic review. Syst Rev. 2012;1:62.

Publisher's Note Springer Nature remains neutral with regard to jurisdictional claims in published maps and institutional affiliations. 